\title{
FAKTOR PENYEBAB IBU HAMIL KURANG ENERGY KRONIK (KEK) DI BPM HJ. MISNI HERAWATI
}

\author{
Veradilla \\ Program Studi DIII Kebidanan STIKES Mitra Adiguna Palembang \\ Jl. Kenten Permai Blok J No 9-12 Bukit Sangkal Palembang 30114 \\ Veradilla90@gmail.com
}

\begin{abstract}
Abstrak
Kurang Energy Kronik (KEK) merupakan salah satu masalah gizi di Indonesia yang biasa dialami oleh ibu hamil, ibu hamil dengan keadaan KEK kemungkinan akan melahirkan bayi BBLR. Dampak dari BBLR adalah anak akan mengalami gangguan pertumbuhan, kecerdasan menurun, imunitas yang randah, meningkatnya morbiditas dan mortalitas serta adanya gangguan metabolic yang dapat meningkatkan resiko penyakit degeratif pada saat dewasa. (Prasetyowati, 2011).Tujuan dari penelitian ini adalah Untuk mengetahui faktor penyebab ibu hamil kurang energy kronik (KEK) di BPM Hj. Misni Herawati Pada penelitian ini pengambilan data dilakukan dengan tekhnik Non random (non probability) sampling metode purposive samping. Dalam penelitian ini menggunakan instrumen dalam bentuk daftar Check List. Check List adalah suatu daftar pengecek, berisi nama subjek dan beberapa gejala/identitas lainnya dari sasaran pengamatan. Pengamat tinggal memberikan tanda check ( $\downarrow$ ) pada daftar tersebut yang menunjukkan adanya gejala/ciri dari sasaran pengamatan. Hasil Penelitian menunjukkan bahwa Dari hasil uji Chi-Square didapatkan nilai $p$ value $=0,000$ hal ini menunjukkan bahwa ada hubungan antara pola makan dengan kekurangan energi kronik pada ibu hamil di BPM. Misni Herawati, Am.Keb Palembang Tahun 2018. Diharapkan agar dapat dijadikan masukkan bagi petugas kesehatan untuk perlunya peran petugas kesehatan dalam meningkatkan pengetahuan tentang KEK pada ibu hamil.
\end{abstract}

Kata Kunci

: Kurang Energy Kronik, Ibu hamil

\begin{abstract}
Chronic Energy Deficiency (KEK) is one of the nutritional problems in Indonesia that is commonly experienced by pregnant women, pregnant women with a KEK condition are likely to give birth to $L B W$ babies. The impact of $L B W$ is that children will experience growth disorders, decreased intelligence, low immunity, increased morbidity and mortality and the presence of metabolic disorders which can increase the risk of degerative diseases in adulthood. (Prasetyowati, 2011). The purpose of this study was to determine the factors that cause chronic energy deficiency pregnant women (KEK) at BPM Hj. Misni Herawati In this study, data collection was carried out by using a non-random (nonprobability) sampling technique using a side purposive method. In this study using an instrument in the form of a Check List. Check List is a check list, containing the name of the subject and several other symptoms / identities of the observation target. The observer only needs to give a check mark ( $)$ on the list which indicates the presence of symptoms / features of the observation target. The results showed that from the Chi-Square test results obtained $p$ value $=0.000$, this indicates that there is a relationship between diet and chronic energy deficiency in pregnant women at BPM. Misni Herawati, Am.Keb Palembang in 2018. It is hoped that it can be used as input for health workers for the need for the role of health workers in increasing knowledge about KEK in pregnant women.
\end{abstract}

Keywords: Chronic Energy Deficiency, Pregnant women

Jurnal Kesehatan dan Pembangunan, Vol. 11, No. 21, Januari 2021 


\section{PENDAHULUAN Latar Belakang}

KEK merupakan salah satu masalah gizi di Indonesia yang biasa dialami oleh ibu hamil, ibu hamil dengan keadaan KEK kemungkinan akan melahirkan bayi BBLR. Dampak dari BBLR adalah anak akan mengalami gangguan pertumbuhan, kecerdasan menurun, imunitas yang randah, meningkatnya morbiditas dan mortalitas serta adanya gangguan metabolic yang dapat meningkatkan resiko penyakit degeratif pada saat dewasa. (Prasetyowati, 2011).

Menurut World Health Organization (WHO) tahun 2012 Kekurangan Energi KroniK (KEK) pada ibu hamil menjadi salah satu penyebab utama terjadinya perdarahan dan infeksi yang merupakan faktor kematian utama ibu di berbagai Negara proporsinya berkisar antara kurang dari 10\% sampai hampir 60\%. (Lestari, 2015)

Prevalensi KEK di negara-negara berkembang seperti Banglades, India, Indonesia, Myanmar, Nepal, Srilanka, dan Thailand adalah $15-47 \%$ yaitu dengan BMI < 18,5. Adapun Negara yang mengalami prevalensi yang tertinggi adalah Banglades yaitu 47\%, sedangkan Indonesia menjadi urutan keempat terbesar setelah India dengan Prevalensi 35,5\% dan yang paling rendah adalah Thailand dengan prevalensi $15-25 \%$. (Lestari, 2015)

Di Indonesia banyak terjadi kasus KEK terutama yang kemungkinan disebabkan karena adanya ketidak seimbangan asupan gizi, sehingga zat gizi yang dibutuhkan tubuh tidak mencukupi. Hal tersebut mengakibatkan pertumbuhan tubuh baik fisik maupun mental tidak sempurna seperti yang seharusnya. (Lestari, 2015)

Terjadinya kekurangan energy kronik pada ibu hamil dapat dipengaruhi oleh banyak faktor seperti faktor sosial ekonomi, faktor jarak kelahiran, faktor paritas, faktor pola makan, dan faktor perilaku. (Menurut Arisman 2009). Apabila ukuran LILA < 23,5 $\mathrm{cm}$ dan anemia $\mathrm{Hb}<11 \mathrm{gr} \%$ penambahan berat badan selama hamil per bulan $<3 \mathrm{~kg}$, ibu hamil mempunyai resiko kekurangan energy kronik (KEK). (Prasetyowati, 2011)

Ibu hamil yang menderita KEK mempunyai resiko kesakitan yang lebih besar terutama pada trimester III kehamilan dibandingkan dengan ibu hamil normal. Akibatnya mereka mempunyai resiko yang lebih besar untuk melahirkan bayi dengan BBLR, kematian saat persalinan, perdarahan, pasca persalinan yang sulit karena lemah dan mudah mengalami gangguan kesehatan. (Depkes RI, 2008)

Kekurangan Energi Kronik (KEK) bukan hanya melemahkan fisik dan membahayakan jiwa ibu, tetapi juga mengancam keselamatan janin. Ibu yang bersikeras hamil dengan status gizi buruk, beresiko melahirkan bayi BBLR 2-3 kali dan kemungkinan bayi mati sebesar 1,5 kali lebih besar disbanding ibu dengan status gizi baik. (Sulistyowati, 2008).

Agar proses kehamilan berjalan normal, maka ibu hamil harus menjaga kesehatannya, dengan memperhatikan pola makan, gaya hidup dan aktifitas fisiknya. Gizi yang baik dibutuhkan oleh ibu hamil untuk mendukung proses pertumbuhan organ pendukung proses kehamilan, proses metabolisme zat gizi, dan mendukung kondisi fetus dan neonates. (Lestari, 2015)

Pertumbuhan janin sangat dipengaruhi oleh status gizi ibu hamil sebelum kehamilan. Jika calon ibu memilih asupan gizi yang cukup dan seimbang, maka akan melahirkan anak yang sehat. Untuk mencapai kondisi ideal ini, banyak dari ibu yang merasa kesulitan dan bermasalah dengan pemenuhan kebutuhan gizi ini. Sampai saat ini masih banyak ibu hamil yang mengalami masalah gizi, khususnya gizi kurang seperti kurang energy kronik (KEK) dan anemia gizi sehingga mempunyai kecenderungan melahirkan bayi dengan berat badan lahir kurang. Gizi kurang pada ibu hamil dapat menyebabakan resiko dan komplikasi pada ibu, antara lain anemia, perdarahan. Pada ibu terhadap proses persalinan ialah secara tidak langsung dapat mempersulit persalinan 
sehingga terjadi persalinan lama, prematuritas, perdarahan setelah persalinan dengan tindakan bahkan kematian ibu meningkat. (Lestari, 2015)

Tahun 2012 Kota Palembang prevalensi bumil KEK sebesar 4,3\% mengalami penurunan disbanding tahun 2011 (5,8\%), dan masih dibawah target nasional dan belum menjadi masalah, namun demikian terdapat 1 Puskesmas yang harus mendapat perhatian yaitu Puskesmas Karyajaya $(12,1 \%)$ karena apabila dibiarkan dikhawatirkan jumlah ibu hamil KEK akan terus meningkat. (Lestari, 2015)

Tahun 2014 di kota Palembang, prevalensi ibu hamil KEK sebesar 4,8\%. Prevalensi tertinggi di wilayah Puskesmas Sukarami $(8,8 \%)$, dan terendah di wilayah Puskesmas Punti Kayu (0,3\%). (Profil Kesehatan Kota Palembang, 2014).

Status gizi janin ditentukan antara lain oleh status gizi ibu pada waktu melahirkan dan keadaan ini dipengaruhi pula oleh status gizi ibu pada waktu konsepsi. Status gizi ibu sewaktu konsepsi dipengaruhi oleh keadaan sosial dan ekonomi ibu sebelum hamil, keadaan kesehatan dan gizi ibu, jarak kelahiran jika yang dikandung bukan anak pertama, paritas, usia kehamilan pertama. Status gizi ibu pada waktu melahirkan ditentukan berdasarkan keadaan kesehatan dan status gizi ibu waktu konsepsi, juga berdasarkan keadaan sosial dan ekonomi waktu hamil, derajat pekerjaan fisik, asupan pangan, dan pernah tidaknya terjangkit penyakit infeksi. (Lestari, 2015)

Berdasarkan data BPM. Misni Herawati, Am.Keb Palembang, tahun 2015 jumlah ibu hamil yang melakukan ANC sebanyak 1.310 orang dan yang mengalami kekurangan energy kronik sebanyak 55 orang, tahun 2016 jumlah ibu hamil yang melakukan ANC sebanyak 1.160 orang dan yang mengalami kekurangan energy kronik sebanyak 36 orang, tahun 2017 jumlah ibu hamil yang melakukan ANC sebanyak 1.402 orang dan yang mengalami kekurangan energy kronik sebanyak 30 orang, pada tahun 2018 di bulan januari jumlah ibu hamil yang melakukan ANC sebanyak 233 orang dan yang mengalami kekurangan energy kronik sebanyak 5 orang, di bulan februari jumlah ibu hamil yang melakukan ANC sebanyak 358 orang dan yang mengalami kekurangan energy kronik sebanyak 20 orang, di bulan maret jumlah ibu hamil yang melakukan ANC sebanyak 324 dan yang mengalami kekurangan energi kronik sebanyak 28 orang, di bulan april jumlah ibu hamil yang melakukan ANC sebanyak 416 orang dan yang mengalami kekurangan energi kronik sebanyak 35 orang, di bulan mei jumlah ibu hamil yang melakukan ANC sebanyak 376 orang dan yang mengalami kekurangan energi kronik sebanyak 26 orang. (Profil BPM. Hj. Misni Herawati, Palembang)

\section{METODOLOGI PENELITIAN}

Pada penelitian ini pengambilan data dilakukan dengan tekhnik Non random (non probability) sampling metode purposive samping. Metode pengumpulan data menggunakan data primer yang diperoleh dari lembar kuisioner yang telah diisi oleh responden. (Lestari, 2015)

\section{Data dan Teknik atau Cara dalam Pengumpulan Data.}

Metode pengumpulan data pada penelitian ini adalah secara penelusuran dan sekunder yang didapat dari data di BPM. Hj. Misni Herawati, Am.Keb Palembang tahun 2018.

Dalam penelitian ini menggunakan instrumen dalam bentuk daftar Check List. Check List adalah suatu daftar pengecek, berisi nama subjek dan beberapa gejala/identitas lainnya dari sasaran pengamatan. Pengamat tinggal memberikan tanda check $(\sqrt{ })$ pada daftar tersebut yang menunjukkan adanya gejala/ciri dari sasaran pengamatan. (Notoatmodjo, 2010) 


\section{Sampel}

Sampel adalah bagian populasi yang akan diteliti atau sebagian jumlah dari karakterisktik yang dimiliki oleh populasi. (Hidayat, 2011)

Sampel adalah sebagian yang diambil dari keseluruhan objek yang diteliti dan dianggap mewakili seluruh populasi (Notoatmodjo, 2010). Sampel dalam

penelitian ini adalah $50 \mathrm{ibu}$ hamil di BPM. Hj. Misni Herawati, Am.Keb Palembang tahun 2018.

\section{Tekhnik Analisis Data}

Untuk melakukan pengolahan data kuantitatif dapat dilakukan dengan cara disajikan dalam bentuk tabel distribusi frekuensi, tabulasi dan perhitunganperhitungan statistic dan data dianalisis univariat dan bivariat secara komputerisasi. (Notoatmodjo, 2010)

\section{Analisa Data Univariat}

Analisa yang dilakukan untuk mengetahui distribusi frekuensi variable independen dan dependen dari hasil penelitian pada umumnya dalam analisa ini hanya menghasilkan distribusi dan presentase dari tiap variable. (Notoatmodjo, 2010)

Analisa univariat dilakukan terhadap tiap variable dari hasil penelitian yaitu variable independen (kekurangan energy kronik) dan variable dependen (ibu hamil) yang dianalisis dengan menggunakan tabel distribusi frekuensi.

\section{Analisa Bivariat}

Analisa bivariate adalah analisa data untuk mengetahui hubungan antara variable independen dengan variable dependen yang dianalisis dengan uji chi-square $\left(x^{2}\right)$ dengan taraf signifikan $(\alpha)=0,05$.

\section{HASIL PENELITIAN}

Penelitian ini dilakukan pada 50 responden dimana kekurangan energi kronik dikelompokkan menjadi 2 kategori yaitu normal (jika ukuran LILA ibu hamil mencapai $\geq 23,5 \mathrm{~cm}$ ) dan tidak normal (jika ukuran LILA ibu hamil $<23,5 \mathrm{~cm}$ ). Adapun tabel distribusi frekuensi kekurangan energi kronik adalah sebagai berikut :

\section{Tabel 4.1}

Distribusi Frekuensi Kekurangan Energi Kronik (KEK)

Pada Ibu Hamil Di BPM. Misni Herawati, Palembang Tahun 2018

\begin{tabular}{|c|c|c|c|}
\hline No & $\begin{array}{c}\text { Kekurangan } \\
\text { Energi Kronik }\end{array}$ & Frekuensi & $\begin{array}{c}\text { Persentase } \\
(\%)\end{array}$ \\
\hline 1. & LILA Normal & 21 & 42 \\
\hline 2. & $\begin{array}{ll}\text { LILA } & \text { Tidak } \\
\text { Normal } & \\
\end{array}$ & 29 & 58 \\
\hline & Jumlah & 50 & 100 \\
\hline
\end{tabular}

Dari tabel 4.1 diatas dapat dilihat bahwa distribusi frekuensi responden yang mempunyai LILA normal sebanyak 21 responden (42\%) dan yang mempunyai LILA tidak normal sebanyak 29 responden $(58 \%)$.

\section{Jarak Kelahiran}

Penelitian ini dilakukan pada 50 responden dimana jarak kelahiran dikelompokkan menjadi 2 kategori yaitu beresiko anemia (jika jarak kelahiran anak < 24 bulan) dan tidak beresiko anemia (jika jarak kelahiran anak $\geq 24$ bulan). Adapun tabel distribusi frekuensi jarak kelahiran adalah sebagai berikut:

\section{Tabel 4.2}

\section{Distribusi Frekuensi Menurut Jarak Kelahiran Anak Ibu Hamil Di BPM. Misni Herawati Palembang Tahun 2018}

\begin{tabular}{llcc}
\hline No & Jarak Kelahiran & Frekuensi & $\begin{array}{c}\text { Persentase } \\
(\%)\end{array}$ \\
\hline 1. & $\begin{array}{l}\text { Beresiko } \\
\text { Anemia }\end{array}$ & 36 & 72 \\
\hline 2. & $\begin{array}{l}\text { Tidak Beresiko } \\
\text { Anemia }\end{array}$ & 14 & 28 \\
\hline & Jumlah & 50 & 100 \\
\hline
\end{tabular}

Dari tabel 4.2 diatas dapat dilihat bahwa distribusi frekuensi responden yang memiliki resiko anemia sebanyak 36 responden (72\%) 
dan responden yang tidak beresiko anemia sebanyak 14 responden $(28 \%)$.

\section{Paritas}

Penelitian ini dilakukan pada 50 responden dimana paritas dikelompokkan menjadi 2 kategori yaitu beresiko tinggi (jika jumlah anak $\geq 4$ anak) dan tidak beresiko (jika jumlah anak < 4 anak). Adapun tabel distribusi frekuensi paritas adalah sebagai berikut:

Tabel 4.3

Distribusi Frekuensi Menurut Paritas Ibu Hamil Di BPM. Misni Herawati, Palembang Tahun 2018

\begin{tabular}{llcc}
\hline No & \multicolumn{1}{c}{ Paritas } & Frekuensi & $\begin{array}{c}\text { Persentase } \\
(\%)\end{array}$ \\
\hline 1. & $\begin{array}{l}\text { Beresiko } \\
\text { Tinggi }\end{array}$ & 24 & 48 \\
\hline 2. & Tidak Beresiko & 26 & 52 \\
\hline & Jumlah & 50 & 100 \\
\hline
\end{tabular}

Dari tabel 4.3 diatas dapat dilihat bahwa distribusi frekuensi responden yang memiliki resiko tinggi sebanyak 24 responden (48\%) dan yang tidak beresiko sebanyak 26 responden $(52 \%)$.

\section{Pola Makan}

Penelitian ini dilakukan pada 50 responden dimana pola makan dikelompokkan menjadi 3 bagian yaitu baik (jika makan $\geq 2$ kali sehari), dan kurang (jika makan < 2 kali sehari). Adapun tabel distribusi frekuensi pola makan adalah sebagai berikut:

Tabel 4.4

Distribusi Frekuensi Menurut Pola Makan Ibu Hamil Di BPM. MIsni Herawati, Palembang Tahun 2018

\begin{tabular}{|c|c|c|c|}
\hline No & $\begin{array}{c}\text { Pola } \\
\text { Makan }\end{array}$ & Frekuensi & $\begin{array}{c}\text { Persentase } \\
(\%)\end{array}$ \\
\hline 1. & Baik & 20 & 40 \\
\hline 2. & Kurang & 30 & 60 \\
\hline \multicolumn{2}{|c|}{ Jumlah } & 50 & 100 \\
\hline
\end{tabular}

Dari tabel 4.4 diatas dapat dilihat bahwa distribusi frekuensi responden yang memiliki pola makan baik sebanyak 20 responden (40\%), dan responden yang memiliki pola makan kurang sebanyak 30 responden $(60 \%)$.

\section{Analisa Bivariat}

Analisa ini dilakukan untuk mengetahui hubungan antara variabel independen (jarak kelahiran, paritas, dan pola makan) dengan variabel dependen (kurang energi kronik (KEK)).Penelitian ini menggunakan uji statistic Chi Square.Menggunakan sistem komputerisasi Statistical Program for Social Science (SPSS) yang merupakan paket atau program statistic yang dibuat untuk mengolah atau menganalisa data. Batas kemaknaan pada $\alpha=0,05$. Jika $p$ value $\leq \alpha=$ 0,05 artinya ada hubungan yang bermakna (signifikan) antara variabel independen dan variabel dependen, jika $\mathrm{p}$ value $>\alpha=0.05$ artinya tidak ada hubungan yang bermakna (signifikan) antara variabel independen dan variabel dependen.

1. Hubungan Antara Jarak Kelahiran dengan Kekurangan Energi Kronik Pada Ibu Hamil

Jumlah responden dalam penelitian ini adalah 50 orang. Analisa bivariate ini digunakan untuk mengetahui hubungan antara jarak kelahiran dengan kekurangan energi kronik pada ibu hamil yang dapat dilihat pada tabel dibawah ini :

Tabel 4.5

Hubungan Antara Jarak Kelahiran dengan Kekurangan Energi Kronik pada Ibu Hamil di BPM. Misni Herawati, Palembang Tahun 2018

\begin{tabular}{|c|c|c|c|c|c|c|c|c|}
\hline \multirow{3}{*}{$\begin{array}{c}\text { Jarak } \\
\text { Kelahiran }\end{array}$} & \multicolumn{4}{|c|}{ Kurang Energi Kronik } & \multirow{3}{*}{$\mathbf{N}$} & \multirow{3}{*}{$\%$} & \multirow{3}{*}{$\begin{array}{c}P \\
\text { value }\end{array}$} & \multirow{3}{*}{ OR } \\
\hline & \multicolumn{2}{|c|}{$\begin{array}{c}\text { LILA } \\
\text { Normal }\end{array}$} & \multicolumn{2}{|c|}{$\begin{array}{c}\text { LILA } \\
\text { Tidak } \\
\text { Normal } \\
\end{array}$} & & & & \\
\hline & $\mathbf{n}$ & $\%$ & $\mathbf{N}$ & $\%$ & & & & \\
\hline Anemia & 12 & 33,3 & 24 & 66,7 & 36 & 100 & & \\
\hline $\begin{array}{l}\text { Tidak } \\
\text { Anemia }\end{array}$ & 9 & 64,3 & 5 & 35,7 & 14 & 100 & 0,095 & 0,278 \\
\hline Jumlah & 21 & & 29 & & 50 & & & \\
\hline
\end{tabular}

Berdasarkan tabel 4.5 diatas diketahui bahwa dari 36 responden yang memiliki resiko anemia terdapat 24 responden $(66,7 \%)$ 
yang memiliki ukuran LILA tidak normal. Sedangkan dari 14 responden yang tidak beresiko anemia terdapat 5 responden $(35,7 \%)$ yang memiliki ukuran LILA tidak normal.

Dari hasil uji Chi-Square didapatkan nilai $p$ value $=0,95$ hal ini menunjukkan bahwa tidakada hubungan antara jarak kelahiran dengan kekurangan energi kronik pada ibu hamil di BPM. Misni Herawati, Am.Keb Palembang Tahun 2018.

Dengan demikian hipotesa awal yang menyatakan ada hubungan antara jarak kelahiran dengan kekurangan energi kronik pada ibu hamil di BPM. Misni Herawati, Am.Keb Palembang Tahun 2018 tidak terbukti secara statistik.

2. Hubungan Antara Paritas dengan Kekurangan Energi Kronik Pada Ibu Hamil

Jumlah responden dalam penelitian ini adalah 50 orang. Analisa bivariate ini digunakan untuk mengetahui hubungan antara paritas dengan kekurangan energi kronik pada ibu hamil yang dapat dilihat pada tabel dibawah ini .

Tabel 4.6

Hubungan Antara Paritas dengan Kekurangan Energi Kronik pada Ibu Hamil di BPM. Misni Herawati, Am.Keb Palembang Tahun 2018

\begin{tabular}{|c|c|c|c|c|c|c|c|}
\hline \multirow{3}{*}{ Paritas } & \multicolumn{4}{|c|}{ Kurang Energi Kronik } & \multirow{3}{*}{$\mathbf{N}$} & \multirow{3}{*}{$\%$} & \multirow{3}{*}{$\begin{array}{c}P \\
\text { Value }\end{array}$} \\
\hline & \multicolumn{2}{|c|}{$\begin{array}{c}\text { LILA } \\
\text { Normal } \\
\end{array}$} & \multicolumn{2}{|c|}{$\begin{array}{c}\text { LILA Tidak } \\
\text { Normal } \\
\end{array}$} & & & \\
\hline & $\mathbf{N}$ & $\%$ & $\mathbf{N}$ & $\%$ & & & \\
\hline Beresiko & 8 & 33,3 & 16 & 13,9 & 24 & 100 & \\
\hline $\begin{array}{l}\text { Tidak } \\
\text { Beresiko }\end{array}$ & 13 & 50 & 13 & 15,1 & 26 & 100 & $\mathbf{0 , 3 6 5}$ \\
\hline Jumlah & 21 & & 29 & & 50 & & \\
\hline
\end{tabular}

Berdasarkan tabel 4.6 diatas diketahui bahwa dari 24 responden yang beresiko tinggi terdapat 16 responden $(13,9 \%)$ yang memiliki ukuran LILA tidak normal. Sedangkan dari 26 responden yang tidak beresiko tinggi terdapat 13 responden $(15,1 \%)$ yang memiliki ukuran LILA tidak normal.
Dari hasil uji Chi-Square didapatkan nilai $p$ value $=0,365$ hal ini menunjukkan bahwa tidak ada hubungan antara paritas dengan kekurangan energi kronik pada ibu hamil di BPM. Misni Herawati, Am.Keb Palembang Tahun 2018.

Dengan demikian hipotesa awal yang menyatakan ada hubungan antara paritas dengan kekurangan energi kronik pada ibu hamil di BPM. Misni Herawati, Am.Keb Palembang Tahun 2018 tidak terbukti secara statistik.

\section{Hubungan Antara Pola Makan dengan Kekurangan Energi Kronik Pada Ibu Hamil}

Jumlah responden dalam penelitian ini adalah 50 orang. Analisa bivariate ini digunakan untuk mengetahui hubungan antara pola makan dengan kekurangan energi kronik pada ibu hamil yang dapat dilihat pada tabel dibawah ini :

Tabel 4.7

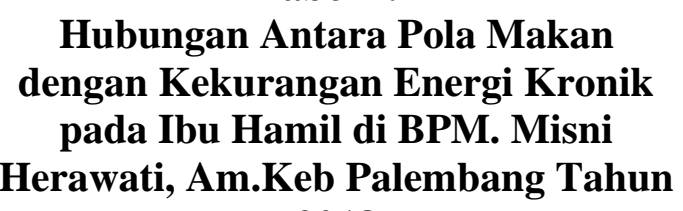

2018

\begin{tabular}{|c|c|c|c|c|c|c|c|c|}
\hline \multirow{3}{*}{$\begin{array}{c}\text { Pola } \\
\text { Makan }\end{array}$} & \multicolumn{4}{|c|}{ Kurang Energi Kronik } & \multirow{3}{*}{$\mathbf{N}$} & \multirow{3}{*}{$\%$} & \multirow{3}{*}{$P$ Value } & \multirow{3}{*}{$O R$} \\
\hline & \multicolumn{2}{|c|}{$\begin{array}{c}\text { LILA } \\
\text { Normal } \\
\end{array}$} & \multicolumn{2}{|c|}{$\begin{array}{c}\text { LILA Tidak } \\
\text { Normal } \\
\end{array}$} & & & & \\
\hline & $\mathbf{N}$ & $\%$ & $\mathbf{N}$ & $\%$ & & & & \\
\hline Baik & 16 & 80 & 4 & 20 & 20 & 100 & & \\
\hline Kurang & 5 & 16,7 & 25 & 83,3 & 30 & 100 & 0,000 & 20,000 \\
\hline$\overline{\text { Jumlah }}$ & 21 & & 29 & & 50 & & & \\
\hline
\end{tabular}

bahwa dari 20 responden yang mempunyai pola makan baik terdapat 4 responden $(20 \%)$ yang memiliki ukuran LILA tidak normal. Sedangkan dari 30 responden yang mempunyai pola makan kurang terdapat 25 responden $(83,3 \%)$ yang memiliki ukuran LILA tidak normal.

Dari hasil uji Chi-Square didapatkan nilai $p$ value $=0,000$ hal ini menunjukkan bahwa ada hubungan antara pola makan 
dengan kekurangan energi kronik pada ibu hamil di BPM. Misni Herawati, Am.Keb Palembang Tahun 2018.

Dengan demikian hipotesa awal yang menyatakan ada hubungan antara pola makan dengan kekurangan energi kronik pada ibu hamil di BPM. Misni Herawati, Am.Keb Palembang Tahun 2018 terbukti secara statistik.

\section{SIMPULAN DAN SARAN Simpulan}

1. Tidak ada hubungan antara jarak kelahiran dengan kekurangan energy kronik pada ibu hamil di BPM. Misni Herawati, Palembang Tahun 2018 dengan nilai $p$ value $=0,095<\alpha(0,05)$.

2. Tidak ada hubungan antara paritas dengan kekurangan energy kronik pada ibu hamil di BPM. Misni Herawati, Palembang Tahun 2018 dengan nilai $p$ value $=0,365>\alpha(0,05)$.

3. Ada hubungan antara pola makan dengan kekurangan energy kronik pada ibu hamil di BPM. Misni Herawati, Palembang Tahun 2018 dengan nilai $p$ value $=0,00<$ $\alpha(0,05)$.

\section{Saran}

\section{Bagi Ibu Hamil}

Ibu hamil sebaiknya menambah pengetahuan mengenai makanan yang bergizi baik dan menu makanan sehat, sehingga asupan makanan ibu hamil lebih berkualitas.

\section{Bagi BPM}

Diharapkan dapat meningkatkan pengetahuan ibu hamil mengenai makanan yang bergizi dengan memberikan konseling tentang gizi simbang sehingga dapat mengurangi kejadian pasien KEK di BPM.

\section{Bagi Institusi Pendidikan}

Diharapkan institusi pendidikan khususnya Stikes Mitra Adiguna dapat menggunakan penelitian ini untuk menambah refersnsi yang dapat digunakan untuk penelitian selanjutnya.

\section{DAFTAR PUSTAKA}

Arisman, 2009. Buku Saku KEK Pada Ibu Hamil Konsep Dan Penatalaksanaan. Jakarta: Trans Info Media

Ellya, Sibagariang. 2010. Gizi dalam kesehatan reproduksi. Jakarta: Trans Info Media

Handayani, Sri. Faktor yang mempengaruhi kekurangan energi kronis pada ibu hamil di Puskesmas Wedi Klaten; 2011. Vol.1; No.4.2011

Hastono. 2008 Analisis data pada bidang kesehatan. Jakarta: Rajawali Pers.

Hidayat. 2008. Metode penelitian kesehatan paradigm kuantitatif. Jakarta: EGC.

Lestari. Faktor yang mempengaruhi resiko kekurangan energi kronik pada ibu hamil di puskesmas keramasan Palembang; 2015. Vol.5; No.9.Januari 2015

Notoatmodjo, Soekidjo. (2010). Metodelogi penelitian kesehatan. Jakarta: Rineka Cipta

Prasetyowati, 2011. Gizi dalam kesehatan reproduksi. ECG: Jakarta

Sulistyowati, 2008. Asuhan kebidanan pada masa kehamilan. Jakarta: Salemba Medika. 